\title{
Regional Students' Vulnerability to Climate in Tunisia: A Spatial Analysis
}

\author{
Zouabi $\mathrm{O}^{1 *}$ and Bouhlila $\mathrm{DS}^{2}$ \\ ${ }^{1}$ University of Tunis El Manar, LAPE \& LEAD, University \\ of Toulon, France \\ 2University of Tunis El Manar, Tunisia \\ *Corresponding author: Oussama Zouabi, University \\ of Tunis El Manar, LAPE \& LEAD, University of Toulon, \\ France
}

Received: September 06, 2021; Accepted: October 08, 2021; Published: October 15, 2021

\begin{abstract}
Weather conditions have not been considered up to date as a factor that contributes to drop out of school in Tunisia. The latter is mainly attributed to poverty, socioeconomic status of students and to a lack of educational infrastructure. This paper is an attempt to introduce geography in explaining dropout in Tunisia. We apply spatial econometric models to show that there is a high degree of spatial clustering in dropout of school. We conclude that students in the north-west region of Tunisia are those who are the most vulnerable to weather conditions and to climate change.
\end{abstract}

Keywords: Climate change; Spatial econometrics; Dropout of school; Vulnerability

\section{Introduction}

Influences of weather changes have been the subject of much inquiry in recent years and a growing body of research «baptized» the climate-economy literature [1] is gaining ground and points out that climate has an impact on a wide range of outcomes including agricultural output; human health; labor productivity; conflict and crime [1].

Students are affected differently to weather conditions even though all are exposed to them. Unfavorable weather conditions (rainy days, hot days, weather shocks) tend to influence students' attendance patterns, students' behavior, students' outcomes and students' learning. Karweil [2] stresses that students' absenteeism is associated to bad weather. Based on the Junior high school attendance data, she reports that the tendency for absence is greater in rainy days. She explains that bad weather may be considered as an additional distraction for students who decide not to come to school when it is rainy; because of the poor road conditions or the dislike for waiting for a bus in a bad weather.

Sudden changes in weather may be predictive of pupil disturbance. In an attempt to relate some simple measurements of weather conditions (temperature, wind speed and rainfall) with the occurrence of disruptive behavior in a secondary school in West Cumbria, Badger and O'Hare [3] find that changes in temperature over the course of the day is connected to pupil behavior. Among the individual weather variables taken into account in this study, temperature is the more powerful predictor of disruptive incidents.

In a survey conducted in Nyando, a district in Kenya, Okuom et al., [4] report that primary school pupils are vulnerable to disasters such as floods and drought and that these environmental factors lead to grade repetition and drop out. Furthermore, they notice that students' frequent absenteeism due to weather conditions lead to low syllabus coverage.

In an attempt to provide evidence on the impact of instructional time loss due to absences and to school closures in elementary and secondary schools in Massachusetts, Goodman [5] exploit the fact that moderate snowfall induces student absences while extreme snowfall induces school closures. Additionally, he finds that each absence due to bad weather decreases math achievement by 0.05 standard deviation.

In investigating the relationship between short-run and longrun weather changes and cognitive performance, Zivin et al., [6] use cognitive ability assessments from the children of the National Longitudinal Survey of Youth (NLSY 79) and data on weather conditions at the country level on the day of the assessment. They provide evidence that short-run changes in temperature lead to decreases in cognitive performance on mathematics but not on reading. However, in the long-run, the relationship between climate and human capital is not statistically significant. This result is explained by individuals acclimating to temperature by doing additional investments to offset short-run weather shocks.

Using administrative data from New York City public schools, Park [7] assesses the impact of temperature on NYC students taking a series of high-stakes exams in June over the period 1999 to 2014. Results suggest that students who take the exams on hot days, exhibit lower scores on high-stakes exams. Additionally, temperature is likely to reduce the amount of learning achieved.

Another strand of literature has examined the link between weather shocks (rain shock, drought) and investment in human capital. Using data on rural children from almost every state in India, from 2005 to 2009, Shah and Steinberg [8] find evidence that during drought years, children report higher school attendance and score higher on simple math tests. Nonetheless, during high rainfall years, children score worse on mathematics and reading tests and are more likely to drop-out. Drought affects agricultural output in India; however, rainfall has positive effects on wage and increase the probability of working for both adults and children in rural India. In the same spirit, an earlier study conducted by Maccini and Yang [9] shows that rainfall was beneficial for Indonesian women born between 1953 and 1974 and living outside an urban area. With 20\% 
higher rainfall, they tend to complete 0.22 more grades of schooling, a consequence of the positive shock (rainfall) to agricultural output and thus income.

In the present study, we are primarily interested in the relationship between weather conditions in Tunisia and students' dropout of school.

Tunisia is known for its Mediterranean climate: hot and dry summers and mild and wet winters. From 1976 to 2000, Tunisia's climate warmed by over $1^{\circ} \mathrm{C}\left(33.9^{\circ} \mathrm{F}\right)$ with increases in both drought and flooding. Global climate projections suggest an average temperature increase by 2050 of $2.1^{\circ} \mathrm{C}\left(35.78^{\circ} \mathrm{F}\right)^{2}$. At present, climate change has not been considered as a factor for students' vulnerability. In the context of increasing climate change impacts which particularly affect the poor and vulnerable children in many regions of Tunisia, it will be essential to incorporate climate change in this study. Our contribution consists of using spatial econometric techniques to take into account the spatial effects. This approach is of paramount importance since it sheds light on the direct and indirect effects of precipitation and temperature of governorate $i$,on students' dropout not only in governorates $\mathrm{i}$ but in neighboring governorates. The spatial methodology used for the purpose of this study considers the spatial autocorrelation between governorates. Our results can be helpful in informing decision-makers regarding students' vulnerability to climate change. They can act in a thorough, rigorous and effective manner in the different regions affected by climate change.

Hence, our paper is structured as follows: the next section describes the methods and data used. Section three, discusses the different results derived from the exploratory analysis of spatial data as well as the results derived from the estimation of the different models used. Section four concludes and provides some policy recommendations.

\section{Data Sources and Methodology}

\section{Data}

The sources of weather data come from Tunisian national institutes: the National Institute of Statistics (INS) and the Institute of Quantitative Economics (IEQ). Besides, we referred to different monthly issues of statistics and statistical issues of Tunisia for the 24 governorates. Data on dropout and illiteracy rates come from Tunisian Labor Market Panel Survey 2014 which was collected in partnership between the Economic Research Forum (ERF) and the Tunisian National Institute of Statistics (INS). Our dependent variable is the number of students dropping out of school in each governorate. The exogenous variables are temperature, precipitation and fathers and mothers illiteracy rates.

This paper introduces spatial methods to analyze the effect of weather on students' dropout in Tunisia. The use of spatial econometrics is justified by the fact that climate variables are inherently spatial in nature. Some of the weather or climate variables which we use in econometric estimation are highly spatially correlated [10]. In addition, spatial models are known to be ideal when quantifying the magnitude of own country impact arising from a change in a variable as well as the spillover impacts on neighboring countries. For instance, a change in a single region variable can have a direct impact on population living in that region $i$ as well as an indirect (or spatial spillover) neighboring regions $j \neq i$. To understand the impact of climate on dropout, we refer to the functional relationship developed by Dett et al. which is as follows:

$$
\mathrm{Y}_{\mathrm{i}}=\mathrm{f}\left(\mathrm{C}_{\mathrm{i}}, \mathrm{X}_{\mathrm{i}}\right)
$$

Where $\mathrm{Y}_{i}$ is the outcome of interest; $\mathrm{C}$ is a vector of climatic variables which includes temperature and precipitation and $\mathbf{X}$ the other explanatory variables which are mother's illiteracy rate and father's illiteracy rate; indexes the different geographic areas. In our case, the outcome variable and the explanatory variables are measured in logs. The inclusion of temperature and precipitation in the regression equation is crucial because both of them tend to be correlated, with a sign that varies by region. Focusing on the impact of one weather variable in isolation will lead to omitted variable bias [10]. A common approach is to begin by spatial autocorrelation tests detecting for spatial autocorrelation or dependence.

\section{Spatial autocorrelation tests}

Several tests are available to gauge the likelihood that model outcomes are affected by spatial autocorrelation. The most frequently applied test is Moran's index. This test looks for the correlation between the values of a variable y (in this case dropout) in each governorate $i$ and the values of the same variable $y$ in the governorates $\mathrm{j}$ that are adjacent to governorate $\mathrm{i}$. We distinguish between the global autocorrelation spatial test and the local autocorrelation spatial test.

Global autocorrelation spatial test: Moran's (I) index was initiated for the first time by Moran. It is defined as:

$$
I=\frac{N \sum_{i} \sum_{j} W_{i j}\left(y_{i}-\bar{y}\right)\left(y_{j}-\bar{y}\right)}{W\left(y_{i}-\bar{y}\right)^{2}}
$$

Where $y_{i}$ is the observed variable in governorate $i, \bar{y}$ is the mean of the values of $\mathrm{N}$ observations, $W_{i j}$ is a matrix of spatial weights and $W=\sum_{(i=1)}^{N} \sum_{(j=1)}^{N} W i j$.

Moran's (I) can take on values from -1 (strong negative spatial autocorrelation) to 0 (no spatial autocorrelation) to 1 (strong positive spatial autocorrelation). In the present study, the global autocorrelation spatial test indicates whether or not governorates with similar dropout rate are clustered, dispersed or randomly dispersed.

Local autocorrelation spatial test: The Local Moran statistic was suggested by Anselin as a way to identify local clusters and spatial outliers. The LISA (Indicator of Spatial Association) index known as the local Moran statistic is defined as follows:

$$
I=\frac{n\left(X_{i}-\bar{X}\right)}{W+\sum_{i=1}^{n}\left(X_{i}-\bar{X}\right)} \sum_{j=1}^{n} W_{i j}\left(X_{i}-\bar{X}\right)
$$

$\mathrm{X}_{\mathrm{i}}$ is the variable related to each governorate $\mathrm{i}$.

The LISA index gives us complete and precise information on the existence of a spatial concentration between the governorates. It allows for a classification of the significant locations as high-high and low-low spatial clusters, and high-low and low-high spatial outliers. More precisely:

$\mathrm{H}-\mathrm{H}^{3}$ : A governorate having high number of students dropping out of school is surrounded by other governorates having also high number of dropout.

L-L ${ }^{4}$ : A governorate having low number of students dropping out of school is surrounded by other governorates having also low number of dropout. 
H-L: A governorate having high number of students dropping out of school is surrounded by other governorates having low number of dropout.

L-H: A governorate having low number of students dropping out of school is surrounded by other governorates having high number of dropout.

$\mathrm{H}-\mathrm{H}$ and L-L are said to have local positive autocorrelation; however $\mathrm{H}-\mathrm{L}$ and $\mathrm{L}-\mathrm{H}$ are said to have local negative autocorrelation.

\section{Econometric model}

Spatial durbin model: When modeling situations involving regional observations, the Spatial Durbin Model is advantageous because the extended regression relationship directly takes into account values of neighboring observations in both the dependent and independent variables.

$$
Y_{i t}=\delta \sum_{(j=1)}^{N} W_{i j} Y_{j t}+X_{i t} \beta+\sum_{(j=1)}^{N} W_{i j} X_{j t} \gamma+\eta_{i t}
$$

$Y_{i t}$ : Total number of students who dropped out of school in governorate $\mathrm{i}$ at time $\mathrm{t}$

$\sum_{(j=1)}^{N} W_{i j} Y_{j t}$ : Total number of students who dropped out of school in a neighboring governorate to $i$.

$\mathrm{X}_{\mathrm{it}}$ : A vector of independent variables: fathers and mothers' illiteracy rates, mean temperature and mean precipitation.

$\sum_{(j=1)}^{N} W_{i j} X_{j t}$ : Independent variables related to neighboring governorate to $i$.

\section{Empirical Analysis}

\section{Global autocorrelation spatial test analysis}

Table 1 displays Moran global test results for students who dropped out of school in 2014. Moran's (I) index shows that the dependent variable is highly correlated with the two contiguity matrices 1 and 2. However, Moran's statistic is negative and not significant for the neighboring matrix W(3).

It is worthy to note that the neighboring matrix $\mathrm{W}(1)$ gives the highest value of Moran's statistic comparing to W(2). We conclude that Moran's statistic is significant and positive when the number of neighboring areas is 1 .

\section{Local autocorrelation spatial test analysis}

Figure 1 highlights the maps that display the spatial pattern of students' dropout. Map 1 shows that our variable of interest exhibits dependence on neighboring centre-west regions of Tunisia which are Kairouan, Sidi Bouzid, Sfax and Mahdia. The spatial dynamics are positive and of type $\mathrm{H}-\mathrm{H}$. In terms of mother's illiteracy rate, map3 reveals its spatial concentration in Jendouba, El Kef, Seliana, Kasserine and Sidi Bouzid. It is only in the north-west and centre-west regions of Tunisia that the spatial dynamics regarding mother's illiteracy are positive. In terms of father's illiteracy rate, it is highly concentrated in north-west region mainly in governorates of Jendouba and El Kef. Sfax is the only region that exhibits negative spatial dynamics in terms of mother's and father's illiteracy rates. Maps 4 and 5 show that both precipitation and temperature present positive indices of type $\mathrm{H}-\mathrm{H}$ and L-L.

With respect to maps 4 and 5, precipitation and temperature present positive indices of type $\mathrm{H}-\mathrm{H}$ and L-L. Map 4 indicates that the following regions: Bizerte, Zaghouan, Jendouba, Manouba and Béja present positive autocorrelation of type $\mathrm{H}-\mathrm{H}$ in 2014. This means for instance that the governorate of Bizerte has high precipitation values and it is surrounded by governorates having also high precipitation values. Despite the importance of these tests in detecting global or local autocorrelation, they do not capture well the spatial interdependence between the different regions of Tunisia regarding the error terms. To overcome this issue, we conduct Multiplier tests of Lagrange.

\section{Multiplier Test of Lagrange}

Table 2 summarizes the different autocorrelation spatial tests. We use Multiplier Test of Lagrange to conduct these tests. The nonrobust autocorrelation test of the dependent variable $\left(\mathrm{LM}_{\delta}\right)$ leads to a rejection of the null hypothesis H0 with the exception of SAR and SEM models which are not significant.

Table 2 shows also that among the three different alternative models, Spatial Durbin model (SDM) is the most adequate. The results of the two non-robust LM tests reject the null hypothesis of the absence of the autocorrelation in the dependent variable, $\mathrm{LM}_{\delta}$ is equal to $0.1689(\mathrm{p}=0.068)$ and reject also the null hypothesis of the absence of autocorrelation in the error terms $(\mathrm{LM} \rho)$ which is equal to 0.0631 $(\mathrm{p}=0.080)$. Both results do not change when we conduct robust LM tests in addition to $\mathrm{LM} \mathrm{SAC}_{\delta}$ and LM SAC $\rho(0.5012(\mathrm{p}=0.077))$.

\section{Results and Discussion}

Table 3 displays the results of the LR test. They lead to the acceptance of the specification with spatial dependence. We find that the value associated with LR test in the SDM model is quite high compared to SEM and SAR models. Similarly, if we compare the value of $\log$-likelihood ( $\log \mathrm{L}$ ) in models, we find a remarkable superiority in the case of the SDM model compared to SEM models.

As have been discussed previously, the SDM model is a general model that can become under the hypothesis $\mathrm{H}_{0}: \gamma=0$, a Spatial Autoregressive Model (SAR) if we connect this hypothesis with the results found in Table 3, we can see that the LR test result ( $\mathrm{Wx}$ 'S = 0 ) which is statistically significant and different from zero and is equal to 18.259 ( $\mathrm{p}=0.001$ ). The comparison of these results with the previous ones encourages us to consider a spatial Durbin model in our econometric analysis.

It is evident that the combination of different factors explain students' dropout in Tunisia. Precipitations exert a direct impact on students' dropout. The results of the estimation of the SDM model show that precipitation and mothers' illiteracy are the main determinants of dropout. Their respective elasticities are 2.529 and 0.592 .

Table 1: Global Moran Statistic: Number of students dropping out of school in 2014.

\begin{tabular}{|c|c|c|c|c|c|}
\hline & Matrix & I. Moran & E(I) & Standard deviation & P-Value \\
\hline Number of students dropping out of school & W(1) & 0.335 & -0.043 & 0.129 \\
\hline
\end{tabular}

***Significant at $1 \%$; ${ }^{* *}$ Significant at $5 \%$; *Significant at $10 \% . W(1)$ is contiguity matrices of order 1 . 


\section{Map 1: Students' dropout}

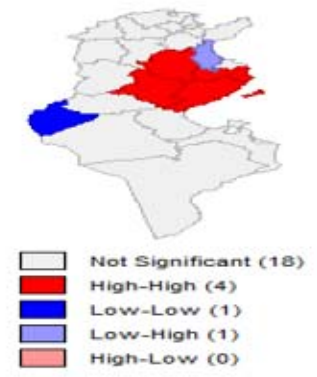

Map 2: Mother's illiteracy rate

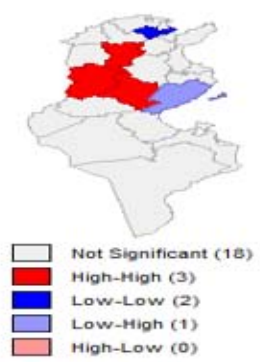

Map 3: Father's illiteracy rate
Map 4: Temperature in ${ }^{\circ} \mathrm{C}$

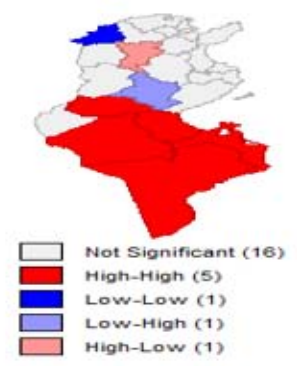

Map 5: Precipitation in $\mathrm{mm}$

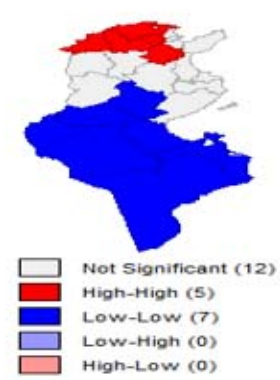

Figure 1: Cluster maps.

Table 2: Results of Multiplier Test of Lagrange.

\begin{tabular}{|c|c|c|c|}
\hline Tests & SAR & SEM & SDM \\
\hline LM $_{\delta}$ & $0.0544(0.815)$ & $11.274^{\star * \star}(0.000)$ & $0.1689^{\star *}(0.068)$ \\
\hline LM $_{\rho}$ & $0.4948(0.481)$ & $2.6034^{\star}(0.106)$ & $0.0631^{\star *}(0.087)$ \\
\hline LM $_{\delta}$ Robust & $0.0348(0.852)$ & $8.699^{\star *}(0.003)$ & $0.4381^{\star *}(0.050)$ \\
\hline LM $_{\rho}$ Robust & $0.4752(0.490)$ & $0.0282(0.866)$ & $0.3324^{\star *}(0.0596)$ \\
\hline LM SAC $_{\delta}$ & $0.5296(0.767)$ & $11.302^{\star *}(0.003)$ & $0.5012^{\star *}(0.077)$ \\
\hline LM SAC $_{\rho}$ & $0.5296(0.767)$ & $11.302^{\star *}(0.003)$ & $0.5012^{\star *}(0.077)$ \\
\hline
\end{tabular}

***Significant at $1 \%$; **Significant at $5 \%$; *Significant at $10 \%$.

Precipitation has a positive and significant spillover effect meaning that the increase of precipitation in a governorate $i$ has not only an impact on students' dropout in that governorate but also in neighboring governorates. The most vulnerable students are concentrated in the north-west region of Tunisia. A common threat in these regions is the increase in flood intensity and frequency due water level increase in Oued Mejerda which is the most important and longest rivers in Tunisia that crosses the northern part of the country from the Algerian border to north of Tunis. Heavy rain fall in this region leads to cut the roads making it difficult for students to reach their schools. It is worthy to note that in early 2003, Tunisia has witnessed cold wave and heavy rainfall especially in the north and central parts of the country. Several governorates in the mountainous area have also experienced below freezing temperatures and snowfalls. Neither houses nor school buildings are built to cope with extreme weather conditions. The heavy rains and flash floods have caused massive damage to the school buildings across areas of the region.
Regarding temperature, table 3 indicates a direct impact as well as an indirect or spatial spillover impact on students' dropout. Children often struggle to concentrate and learn when the weather is hot. Heat stress has been shown to reduce concentration, which may further diminish cognitive and/or physical performance (Anderson and Anderson 1984). Public school buildings lack air conditioning equipment and don't have any form of air conditioning available. In addition, and given the fact that many schools are not easily accessible, many children are getting tired from walking long distances to reach school and prefer dropping out of school. Besides, the current dry and hot weather conditions in Tunisia are considerably increasing the risk for fires. Sometimes, hot wind from the south contributes to worsen the situation, spreading easily any fire outbreak to cause widespread destruction: destruction of houses and schools, displacing families. All these elements contribute to increase students' dropout.

Turning to the direct effect of mothers' illiteracy on students' dropout, it is not surprising that the impact is positive and significant. Having illiterate mother increases the vulnerability of children to drop out of school. On the contrary, father's illiteracy has a negative and significant impact on their children's dropout. Huge literature is dedicated to the positive influence of mother's education on students' achievement as well as the impact of socioeconomic status [11-15].

\section{Conclusion and Recommendations}

Research on the causes of dropout has mainly focused on students' economic status and poverty. Our present study highlights the fact that students in Tunisia are vulnerable to weather conditions and it is may be the poor who are the most vulnerable since wealthy families 
Table 3: Estimation results of SAR, SEM and SDM W (1) models.

\begin{tabular}{|c|c|c|c|c|c|c|}
\hline Model & \multicolumn{2}{|c|}{ SAR } & \multicolumn{2}{|c|}{ SEM } & \multicolumn{2}{|c|}{ SDM } \\
\hline M & 0.0534 & $(0.164)$ & 0.469 & $(0.245)$ & $0.592^{*}$ & $(0.104)$ \\
\hline $\mathbf{F}$ & $-0.047^{\star *}$ & $(0.047)$ & $-0^{2} .371^{\star *}$ & $(0.088)$ & $-0.772^{\star \star \star}$ & $(0.000)$ \\
\hline $\mathbf{P}$ & 0.304 & $(0.854)$ & $0.071^{\star \star}$ & $(0.069)$ & $2.529 \star \star$ & $(0.073)$ \\
\hline $\mathbf{T}$ & 0.015 & $(0.181)$ & 0.102 & $(0.288)$ & $0.184^{\star *}$ & $(0.083)$ \\
\hline W1X-M & & & & & $0.067^{\star \star}$ & $(0.005)$ \\
\hline W1X-F & & & & & $-0.0428^{\star *}$ & $(0.003)$ \\
\hline W1X-P & & & & & -0.144 & $(0.206)$ \\
\hline W1X-T & & & & & 0.082 & $(0.219)$ \\
\hline $\mathbf{R}^{2}$ & \multicolumn{2}{|c|}{0.253} & \multicolumn{2}{|c|}{0.2145} & \multicolumn{2}{|c|}{0.580} \\
\hline$\overline{R^{2}}$ & \multicolumn{2}{|c|}{0.142} & \multicolumn{2}{|c|}{0.096} & \multicolumn{2}{|c|}{0.403} \\
\hline Log-L & \multicolumn{2}{|c|}{-22.61} & \multicolumn{2}{|c|}{-22.21} & \multicolumn{2}{|c|}{-15.84} \\
\hline LR test $\left(W x^{\prime} S=0\right)$ & 1.6710 & $(0.196)$ & $3.389 * \star$ & 0.065 & $18.259 * * *$ & $(0.001)$ \\
\hline Wald test & 6.454 & $(0.167)$ & 3.992 & $(0.407)$ & $21.165^{\star \star}$ & $(0.006)$ \\
\hline F-test & 1.6135 & $(0.209)$ & 0.9982 & $(0.431)$ & $2.645^{\star \star}$ & $(0.046)$ \\
\hline Direct effect M & -0.150 & $(0.304)$ & & & 0.377 & $(0.517)$ \\
\hline Indirect effect M & $-0.027^{*}$ & $(0.058)$ & & & $0.0884^{*}$ & $(0.121)$ \\
\hline Total effect M & -0.178 & $(0.361)$ & & & 0.462 & $(0.634)$ \\
\hline Direct effect $F$ & 0.242 & $(0.332)$ & & & -0.159 & $(0.323)$ \\
\hline Indirect effect $F$ & $0.044^{* *}$ & $(0.060)$ & & & $-0.037^{\star *}$ & $(0.075)$ \\
\hline Total effect $F$ & 0.286 & $(0.392)$ & & & -0.1972 & $(0.400)$ \\
\hline Direct effect $P$ & 0.271 & $(0.225)$ & & & 2.1543 & (1.795) \\
\hline Indirect effect $P$ & 0.050 & $(1.20)$ & & & 0.508 & $(0.423)$ \\
\hline Total effect $P$ & 0.321 & $(0.267)$ & & & 2.66 & $(2.21)$ \\
\hline Direct effect $T$ & $0.127^{*}$ & $(0.145)$ & & & $0.148^{*}$ & (0.169) \\
\hline Indirect effect $T$ & $0.023^{\star *}$ & $(0.026)$ & & & $0.035^{\star \star}$ & $(0.04)$ \\
\hline Total effect $T$ & 0.151 & $(0.172)$ & & & $0.183^{*}$ & $(0.175)$ \\
\hline
\end{tabular}

***Significant at $1 \%$; ${ }^{* *}$ Significant at $5 \%$; ${ }^{*}$ Significant at $10 \%$. Values between brackets correspond to t-Student.

are able to recover from natural disasters and absorb losses more quickly than poor people. It also appears from our study that students living in north-west region of Tunisia are those who are the most vulnerable. With less education, children will learn less and are more likely to live in poverty. Our results suggest that policy-makers need to put forth welfare-enhancing public policy interventions to remedy to dropout problems due to weather conditions. The most vulnerable students are in need of assistance when an extreme weather event hits, to enable them to reach schools safely. Furthermore, reducing vulnerability to climate impacts should be integrated into prior plans established by the ministry of education.

\section{References}

1. Dell Melissa, Benjamin F Jones, Benjamin A. Olken. "Temperature shocks and economic growth: Evidence from the last half century". American Economic Journal: Macroeconomics. 2012; 4.3: 66-95.

2. Karweil NL. Rainy Days and Mondays, Report No. 162 (Baltimore Md. John Hopkins University, Center for the Study of the Sociological Organisation of schools). 1973.

3. Badger B, O'Hare E. Disruptive Behaviour and Weather Patterns in a West Cumbria Secondary School. British Educational Research Journal. 1989; 15: 89-94.

4. Okuom HA, Simatwa EMW, Maureen OA, Wichenje KM. 'Assessment of factors that contribute to repetition and dropout of pupils in primary schools in flood prone areas of Nyando District, Kenya: An analytical study', Educational Research. 2012; 3: 194.

5. Goodman J. "Flaking out: Student absences and snow days as disruptions of instructional time". No. w20221. National Bureau of Economic Research. 2014.

6. Joshua S Graff Zivin, Solomon M Hsiang, Matthew J Neidell. Temperature and Human Capital in the Short- and Long-Run. NBER Working Paper No. 2015; 21157.

7. Park J. Temperature, Test Scores, and Educational Attainment. Working Paper, Department of Economics, Harvard University. 2016

8. Shah M, Millett B Steinberg. Drought of opportunities: contemporaneous and long term impacts of rainfall shocks on human capital. NBER Working Paper. 2013; 19140

9. Maccini S, Yang D. "Under the Weather: Health, Schooling, and Economic Consequences of Early-Life Rainfall”. American Economic Review. 2009; 99.

10. Auffhammer Maximilian, Solomon Hsiang, Wolfram Schlenker, Adam Sobel. "Global Climate Models: A User Guide for Economists". Review of Environmental Economics and Policy. 2011.

11. Chiu MM, Khoo L. Effects of resources, inequality, and privilege bias on achievement: Country, school, and student level analyses. American Educational Research Journal. 2005; 42: 575-603.

12. Sirin SR. Socioeconomic status and academic achievement: A meta-analytic review of research. Review of Educational Research. 2005; 75: 415-453.

13. White KR. The relation between socioeconomic status and educationa achievement. Psychological Bulletin. 1982; 91: 461-481.

14. Bockstael NE. Modeling Economics and Ecology: The Importance of a Spatial Perspective. American Journal of Agricultural Economics. 1996; 78: 1168-1180.

15. Mudavanhu C. The impact of flood disasters on child education in Muzaraban District, Zimbabwe Jàmbá: Journal of Disaster Risk Studies. 2014; 6: 1-8. 